\title{
Analisis kestabilan pantai berdasarkan karakteristik sedimen di Pulau Maitara, Kota Tidore Kepulauan
}

\author{
(Analysis of coastal stability based on sediment characteristics at Maitara Island, \\ Tidore Islands City)
}

\author{
Najamuddin ${ }^{1}$, Irmalita Tahir ${ }^{1}$ \\ ${ }^{1}$ Prodi Ilmu Kelautan, FPIK-Universitas Khairun, Ternate
}

\begin{abstract}
ABSTRAK
Karakterisitik sedimen yang menyusun suatu wilayah pantai dapat dijadikan indikator untuk menentukan kestabilan wilayah pantai. Tujuan penelitian adalah mengklasifikasi kategori tekstur sedimen, menentukan karakteristik sedimen penyusun pantai, dan menentukan tingkat kestabilan pantai perairan Pulau Maitara. Klasifikasi kategori tekstur sedimen menggunakan skala Wenworth dan analisis karakteristik sedimen dilakukan dengan aplikasi program GSA (grain size analysis). Hasil penelitian diperoleh kategori tekstur sedimen penyusun pantai Pulau Maitara terdiri dari 6 kategori yaitu pasir sangat kasar, pasir kasar, pasir sedang, pasir halus, pasir sangat halus dan lumpur dengan kategori tekstur sedimen yang dominan menyusun pantai pulau Maitara adalah jenis pasir sedang dan pasir halus. Karakteristik sedimen penyusun pantai Pulau Maitara untuk kategori sorting adalah tersortir sedang (moderately sorted), skewness adalah mendekati simetris (nearly symmetrical), dan kurtosis adalah tumpul (platykurtic). Tekstur dan karakteristik sedimen pantai yang menyusun Pulau Maitara menunjukkan indikasi bahwa dibagian timur Pulau Maitara merupakan wilayah pantai yang stabil. Adapun di wilayah pantai bagian utara dan selatan mengindikasikan wilayah pantai yang mengalami erosi.
\end{abstract}

Kata kunci: kestabilan pantai, tekstur, sedimen, Pulau Maitara

\section{ABSTRACT}

Characteristic of sediment that compile coastal zone was coastal stability indicator. The aim of this research were classify the texture of sediment and determine characteristic of coastal sediment, and analysis coastal stability of Maitara Island. Classify of sediment texture based on the Wenworth scale and sediment characteristic by application of Grain Size Analysis Software. Result of this research found there were six category of sediment texture of Maitara Island. They were very coarse sand, coarse sand, medium sand, fine sand, very fine sand and silt. Medium sand and fine sand category as dominan sediment texture that compile coastal of Maitara Island. The characteristic of coastal compile sediment of Maitara Island consist of sorting by moderately sorted, skewness by nearly simetrical, and kurtosis by platicurtic. The characteristic and texture of sediment indicated that the eastern coastal of Maitara island was stable coast, but in the northern and southern island was erosion coast.

Keywords : coastal stability, texture, sediment, Maitara Island. 


\section{Pendahuluan}

Aktifitas pembangunan yang secara langsung memanfaatkan ruang wilayah pantai menyebabkan termodifikasinya sistem dinamika perairan yang kemudian berdampak pada potensi terjadinya suksesi ekologi bagi organisme dan komunitas pantai. Terkait dengan profil pantai, dinamika perairan pantai menjadi salah satu kontrol pembentuk profil pantai di perairan dangkal. Variabel dinamika berupa pola perambatan arus dan gelombang beserta energi yang berinteraksi dengan perairan dangkal. Tingkat interaksi yang dihasilkan merupakan suatu bentuk tekanan yang akan merubah karakteristik material sedimen yang mengakibatkan terjadinya perubahan dan pergeseran garis pantai (Komar, 1975). Proses perubahan material sedimen penyusun pantai dapat terjadi dalam bentuk perubahan karakteristik material dan pengangkutan material dari suatu wilayah pantai ke wilayah pantai yang lain. Oleh karena itu material sedimen penyusun pantai menjadi indikator penting dalam menentukan tingkat kestabilan suatu wilayah pantai. Tingkat kestabilan pantai dapat diukur dari proses sedimentasi atau erosi yang terjadi di wilayah pantai yang merupakan hasil interaksi antara kerja energi angin, arus, gelombang, dan pasang surut terhadap material sedimen penyusun pantai (Folk, 1974).

Pulau Maitara yang terletak antara Pulau Ternate dan Tidore menyebabkan dinamika pantai yang berkembang di wilayah ini sangat dipengaruhi oleh karakteristik oseanografi yang berkembang pada kedua pulau tersebut terutama pada aspek pembentukan profil pantai dan karakteristik material pantainya. Posisi Pulau Maitara sebagai jalur transportasi laut, dinama proses kerja energi gelombang dan arus yang terbangkit dari kegiatan pelayaran laut juga akan memberikan kontribusi terhadap angkutan material sedimen pantai dalam bentuk terjadinya proses pengadukan material kohesif dari dasar laut, perpindahan material secara horisontal maupun pengendapan kembali material sedimen sehingga berdampak pada dinamika garis pantai yang terbentuk.

Penelitian ini bertujuan untuk menentukan klasifikasi tekstur sedimen, karakteristik tekstur sedimen penyusun pantai dan menentukan tingkat kestabilan pantai di perairan pantai Pulau Maitara. Klasifikasi kategori tekstur sedimen menggunakan skala Wenworth dan analisis karakteristik butiran sedimen dilakukan dengan aplikasi program GSA (grain size analysis).

\section{Metode penelitian}

\subsection{Lokasi penelitian}

Lokasi pengambilan sampel dilakukan di perairan pantai Pulau Maitara, Kota Tidore Kepulauan, analisis sampel dilakukan di Laboratorium Mekanika Tanah Fakultas Teknik Universitas Khairun (Gambar 1)

\subsection{Penentuan titik sampling}

Titik pengambilan sampel terdiri dari 3 stasiun masing-masing stasiun 1 terletak di bagian utara Pulau Maitara, stasiun 2 terletak di bagian timur Pulau Maitara dan stasiun 3 terletak di bagian selatan Pulau Maitara. Adapun bagian barat Pulau Maitara tidak diamati karena merupakan pantai berbentuk tebing yang curam. Pada tiap stasiun diambil 6 titik sampling yang dilakukan secara acak (random sampling method) (Gambar 2). 


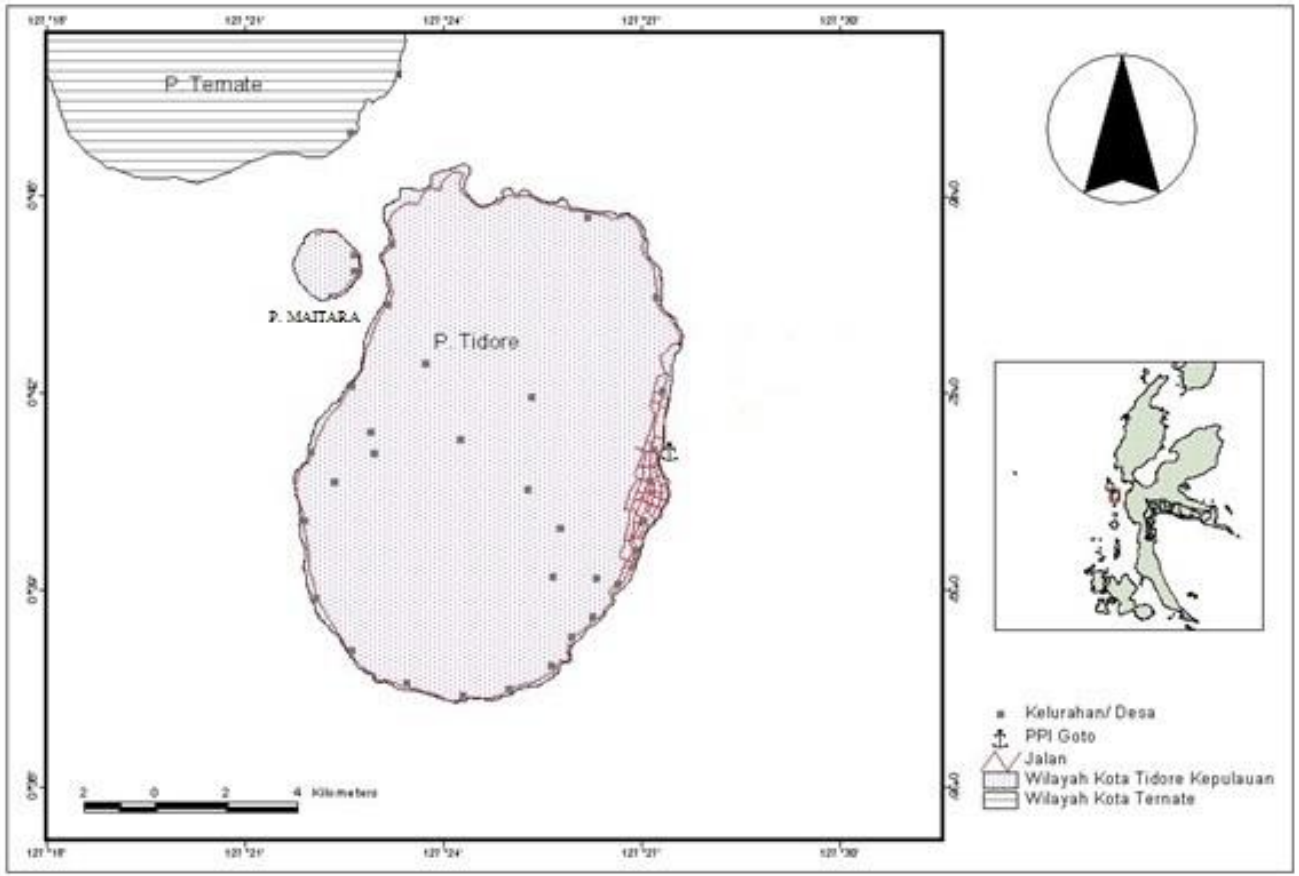

Gambar 1. Peta lokasi penelitian

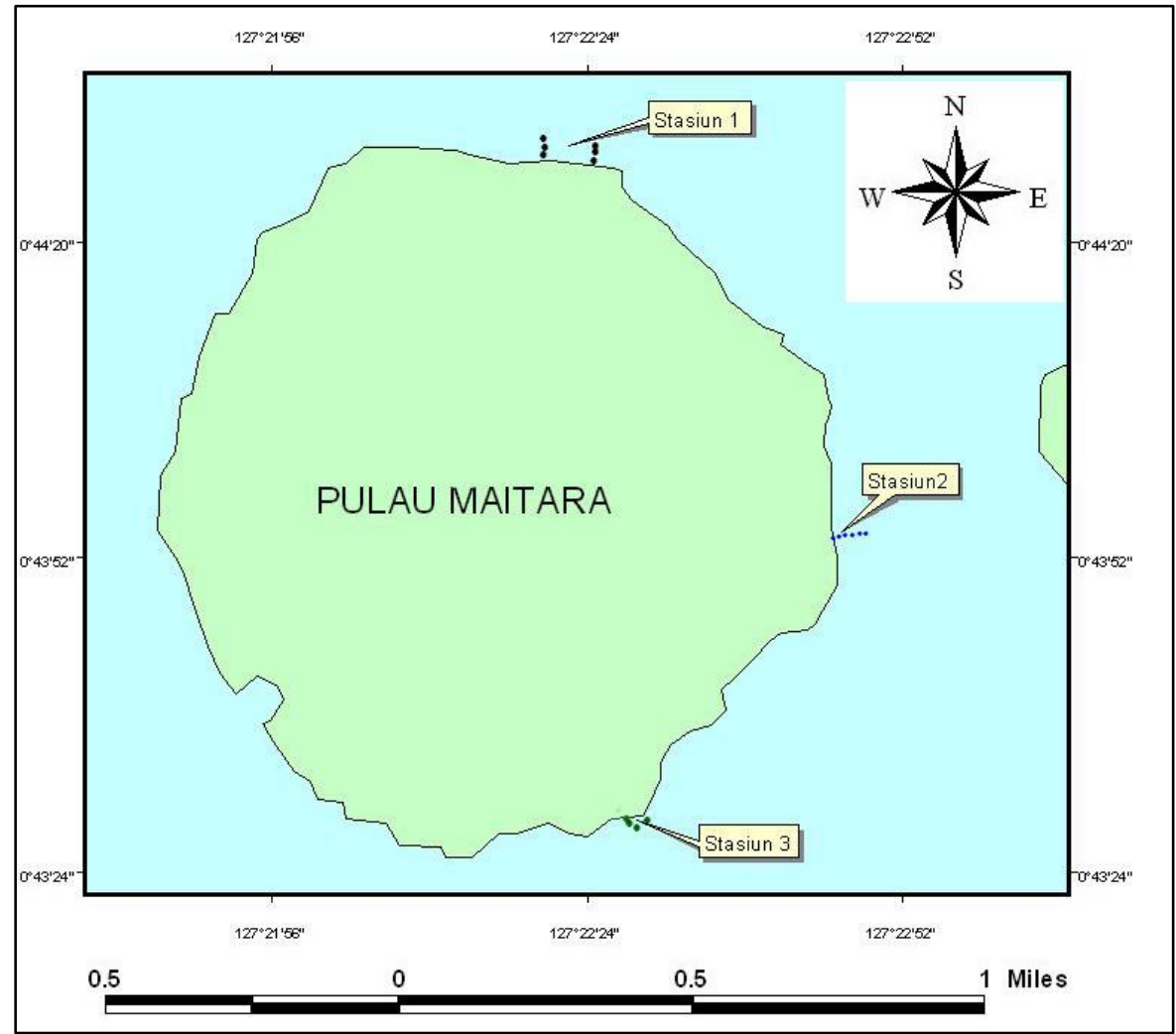

Gambar 2. Stasiun dan titik sampling lokasi penelitian 


\subsection{Metode pengambilan dan pengayakan sampel sedimen}

Pengambilan sampel sedimen dilakukan dengan menggunakan sediment core. Sampel sedimen yang tercuplik kemudian dimasukkan dalam kantong plastik dan diberi label. Sampel sedimen selanjutnya dibawa ke laboratorium untuk dilakukan proses pengeringan dan pemisahan ukuran butiran dengan metode saringan (ayakan).

Alat penyaring memiliki ukuran mata ayakan menurut skala ukuran diameter butiran sedimen. Ukuran dari mata ayakan didasarkan pada sistem skala Wenworth. Alat penyaring yang digunakan terdiri dari delapan tingkatan mata ayakan dengan ukuran diameter masing-masing $1.36 \mathrm{~mm}, 0.89 \mathrm{~mm}, 0.60 \mathrm{~mm}, 0.42 \mathrm{~mm}, 0.30 \mathrm{~mm}, 0.15$ $\mathrm{mm}, 0.07 \mathrm{~mm}$, dan $<0.07 \mathrm{~mm}$.

Setelah proses pengayakan selesai, selanjutnya dilakukan penimbangan berat sampel sedimen yang tersaring pada tiap tingkatan ayakan dengan timbangan digital. Hasil penimbangan kemudian dicatat pada lembaran isian data dan dilakukan klasifikasi tekstur sedimen. Metode pengayakan berdasarkan (Lewis, 1984).

\subsection{Klasifikasi tekstur dan karakteristik sedimen}

Klasifikasi tekstur sedimen dilakukan dengan pengelompokan hasil penyaringan berdasarkan diameter saringan yang digunakan dan pengelompokan ukuran butiran diameter sedimen menurut skala Wenworth.

Penentuan karakteristik sedimen yang terdiri dari nilai rataan empirik (mean), pemilahan (sorting), kemencengan (skewness), dan keruncingan (kurtosis) dilakukan dengan menggunakan aplikasi program GSA (grain size analysis) oleh Fay (1988).

\section{Hasil dan Pembahasan}

\subsection{Klasifikasi tekstur sedimen}

Kategori tekstur sedimen penyusun pantai Pulau Maitara yang diperoleh pada ke tiga stasiun pengamatan terdiri dari 6 kategori yaitu pasir sangat kasar (very coarse sand) dengan diameter butiran antara 1-2 mm, pasir kasar (coarse sand) dengan diameter butiran antara 0,5-1 mm, pasir sedang (medium sand) dengan diameter butiran antara 0,25-0,5 mm, pasir halus (fine sand) dengan diameter butiran antara 0,125-0,25 $\mathrm{mm}$, pasir sangat halus (very fine sand) dengan diameter butiran antara 0,062-0,125 mm dan lumpur (silt) dengan diameter butiran <0,061 $\mathrm{mm}$. Persentase kategori butiran sedimen pada tiap stasiun pengamatan disajikan secara lengkap pada gambar 3,4, dan 5 di bawah ini.

Komposisi sebaran butiran sedimen penyusun pantai Pulau Maitara pada stasiun I didominasi oleh kategori butiran sedimen yaitu pasir sedang (medium sand) dengan rata-rata persentase sebesar 34,94\%, pasir halus (fine sand) dengan rata-rata persentase sebesar 32,65\% dan pasir kasar (coarse sand) dengan rata-rata persentase sebesar $21,53 \%$.

Kondisi umum pulau Maitara merupakan wilayah yang terlindung karena terletak antara pulau Ternate dan Tidore. Stasiun I yang terletak pada bagian utara pulau Maitara merupakan wilayah yang berhadapan dengan pulau Ternate dengan kondisi yang agak terbuka pada arah barat laut pulau yang berhadapan dengan Laut Maluku. Kondisi yang agak serupa dijumpai pada stasiun III yaitu pada bagian selatan Pulau Maitara berhadapan dengan pulau Tidore dan kondisi lebih terbuka ke arah barat daya. Keadaan ini kemudian berpengaruh terhadap dinamika oseanografi yang berkembang di bagian utara dan selatan pulau. 


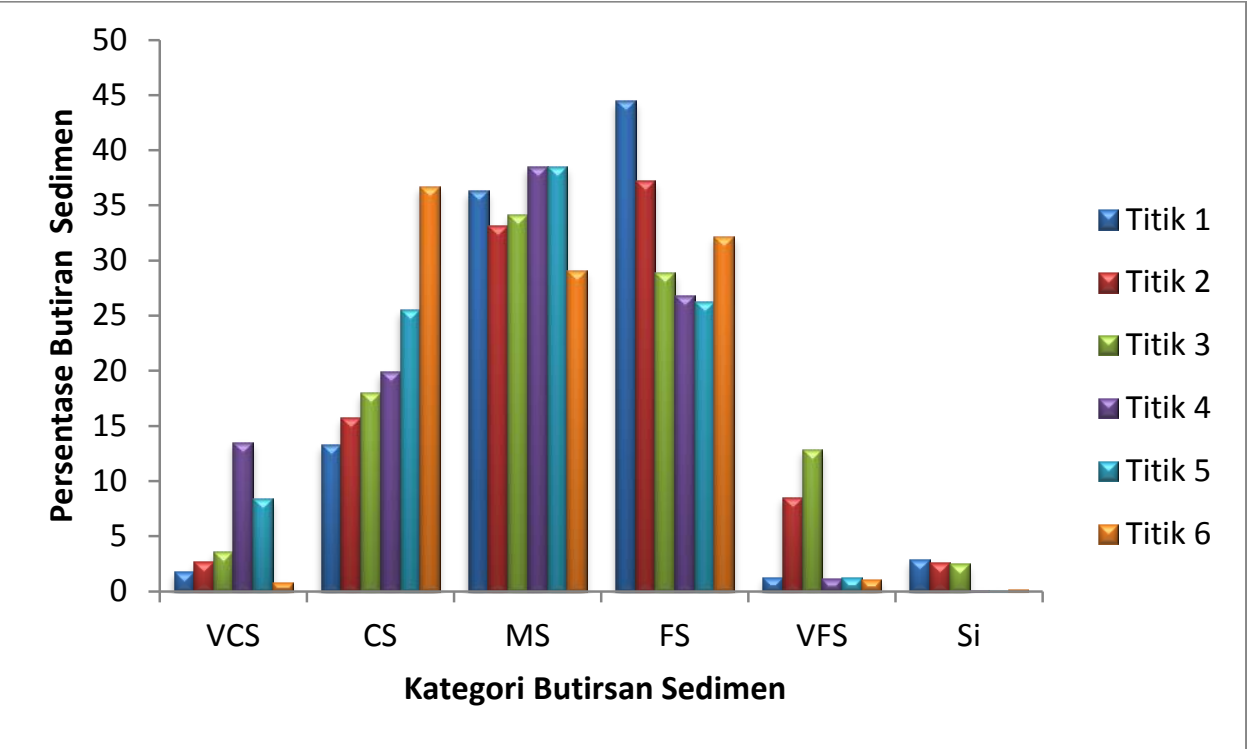

Keterangan :

VCS = pasir sangat kasar

$\mathrm{CS}=$ pasir kasar

MS = pasir sedang

FS $\quad=$ pasir halus

VFS $=$ pasir sangat halus

$\mathrm{Si}=$ lumpur

Gambar 3. Persentase tekstur sedimen pada stasiun I

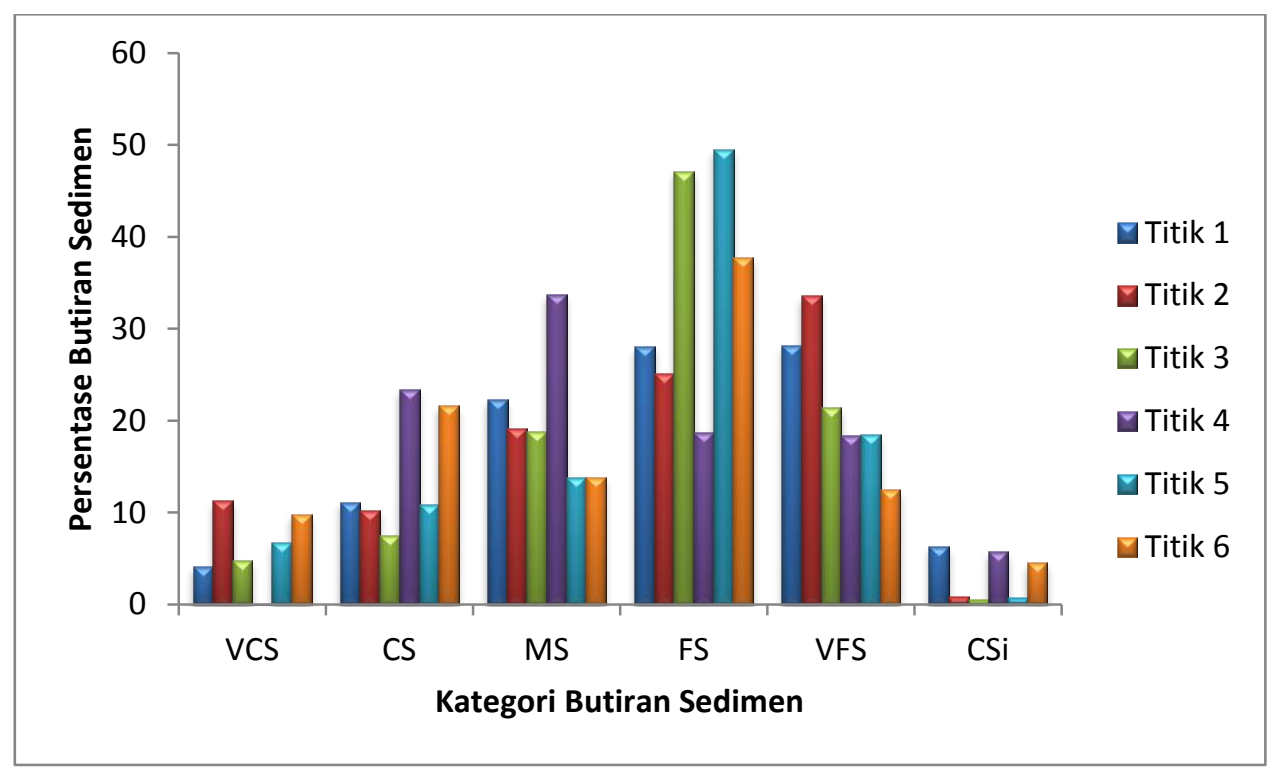

Keterangan :

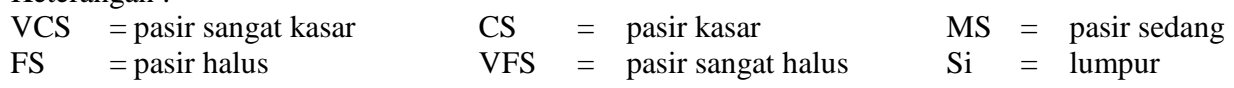

Gambar 4. Persentase tekstur sedimen pada stasiun II

Sebaran butiran sedimen penyusun pantai Pulau Maitara pada stasiun II komposisinya lebih didominasi oleh kategori butiran sedimen pasir halus (fine sand) dengan rata-rata persentase sebesar $34,36 \%$, kemudian pasir sangat halus (very fine 
sand) dengan rata-rata persentase sebesar 22,08\%, dan pasir sedang (medium sand) dengan rata-rata persentase sebesar $20,25 \%$.

Kondisi pada stasiun II agak berbeda dengan kondisi di stasiun I dan III, dimana pada stasiun II di bagian timur pulau Maitara merupakan daerah yang lebih tertutup karena terlindung oleh Pulau Tidore sehingga bangkitan arus dan gelombang di wilayah ini lebih kecil dibanding pada stasiun I dan III. Akibatnya material penyusun pantai di stasiun II lebih dominan ditemukan pasir halus dan sangat halus.

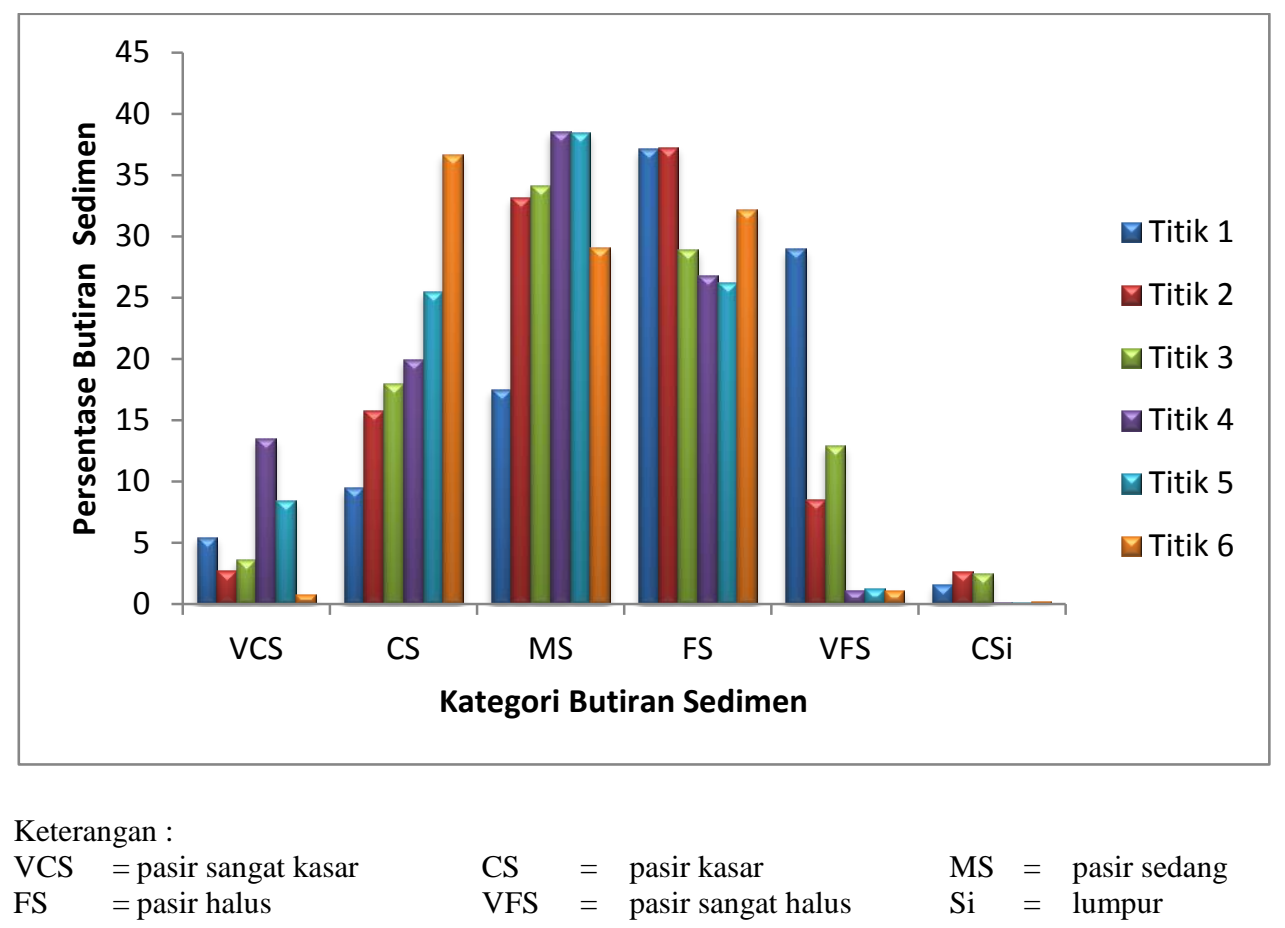

Gambar 5. Persentase tekstur sedimen pada stasiun III

Butiran sedimen penyusun pantai Pulau Maitara pada stasiun III komposisinya serupa dengan stasiun I yang lebih didominasi oleh kategori butiran sedimen pasir sedang (medium sand) dengan rata-rata persentase sebesar 31,80\%, pasir halus (fine sand) dengan rata-rata persentase sebesar 31,42\% dan pasir kasar (coarse sand) dengan rata-rata persentase sebesar $20,90 \%$.

\subsection{Karakteristik tekstur sedimen}

Parameter karakteristik tekstur sedimen yang dianalisis terdiri dari kategori pemilahan (sorting), kemencengan (skewness), dan keruncingan (kurtosis).

\subsubsection{Pemilahan (Sorting)}

Sorting adalah ukuran keseragaman ukuran butiran sedimen. Nilai keseragaman butiran sedimen terdiri dari keseragaman ukuran, bentuk, dan berat jenis. Proses pemilahan butiran sedimen secara alami akan terpisah dari gabungan partikel tak seragam oleh tenaga pengangkut terutama oleh energi arus. Hasil analisis pemilahan (sorting) butiran sedimen di lokasi penelitian disajikan pada tabel di bawah ini. 
Tabel 1. Parameter nilai dan kategori sorting sedimen pantai Pulau Maitara

\begin{tabular}{|c|c|c|c|}
\hline \multirow{2}{*}{ Stasiun } & \multirow{2}{*}{ Titik } & \multicolumn{2}{|c|}{ Pemilahan (Sorting) } \\
\hline & & Nilai $(\pi)$ & Kategori \\
\hline \multirow{6}{*}{ I } & 1 & 1,42 & Tersortir buruk \\
\hline & 2 & 1,39 & Tersortir sedang \\
\hline & 3 & 1,15 & Tersortir sedang \\
\hline & 4 & 1,42 & Tersortir buruk \\
\hline & 5 & 1,2 & Tersortir sedang \\
\hline & 6 & 1,41 & Tersortir buruk \\
\hline \multirow{6}{*}{ II } & 1 & 1,08 & Tersortir sedang \\
\hline & 2 & 1,20 & Tersortir sedang \\
\hline & 3 & 1,30 & Tersortir sedang \\
\hline & 4 & 1,20 & Tersortir sedang \\
\hline & 5 & 1,10 & Tersortir sedang \\
\hline & 6 & 0,85 & Tersortir sedang \\
\hline \multirow{6}{*}{ III } & 1 & 1,21 & Tersortir sedang \\
\hline & 2 & 1,41 & Tersortir buruk \\
\hline & 3 & 1,42 & Tersortir buruk \\
\hline & 4 & 1,31 & Tersortir sedang \\
\hline & 5 & 1,36 & Tersortir sedang \\
\hline & 6 & 1,39 & Tersortir sedang \\
\hline
\end{tabular}

Distribusi nilai dan kategori sorting terlihat bahwa pada stasiun II memiliki karakteristik butiran sedimen terpilah sedang atau distribusi sedimen penyusun pantainya cenderung seragam. Sementara pada stasiun I dan III distribusi butiran sedimen penyusun pantai cenderung tidak seragam.

Karakteristik nilai dan kategori sorting material penyusun pantai berkaitan dengan nilai porositas sedimennya, dimana jika distribusi sedimen cenderung seragam berarti nilai porositas materialnya besar. Hal ini juga menjadi indikator tingkat kestabilan pantai yang lebih besar berarti terjadi proses deposisi material pantai karena energi arus dan gelombang yang cukup kecil. Kondisi tersebut ditemukan pada lokasi penelitian khususnya stasiun II. Triatmojo, 1999 mengemukakan bahwa fungsi gelombang dan arus sangat berperan penting dalam proses pengangkutan material sedimen. Pada pantai dengan gerakan arus dan gelombang yang relatif kecil akan membentuk pantai yang tersusun dari material pasir halus.

\subsubsection{Kemencengan (Skewness)}

Kemencengan adalah ukuran ketidaksimetrisan atau kesimetrisan suatu butiran sedimen. Kriteria butiran sedimen untuk karakteristik kemencengan terdiri dari kemencengan negatif artinya distribusi butiran sedimen cenderung ke ukuran kasar (butiran besar), kemencengan positif artinya distribusi butiran sedimen cenderung ke ukuran butiran halus/kecil dan simetris artinya butiran sedimen berada pada butiran sedang. Hasil analisis karakteristik kemencengan (skewness) material sedimen penyusun pantai pulau Maitara disajikan pada tabel 2. 
Berdasarkan hasil analisis skewness terlihat bahwa pada stasiun II menunjukkan indikator pantai yang lebih stabil dengan distribusi butiran sedimen yang mendekati kategori simetris atau terindikasi pantai yang seimbang antara deposisi dan erosi. Agak berbeda pada stasiun I dan III menunjukkan pantai yang kurang stabil dan cenderung mengalami proses erosi yang diindikasikan oleh distribusi butiran sedimen dengan kategori negatif (butiran sedimen cenderung ke pola ukuran butiran kasar/besar).

Tabel 2. Parameter nilai dan kategori skewness sedimen pantai Pulau Maitara

\begin{tabular}{cccc}
\hline \multirow{2}{*}{ Stasiun } & Titik & \multicolumn{2}{c}{ Kemencengan (Skewness) } \\
\cline { 3 - 4 } & & Nilai $(\boldsymbol{\pi})$ & Kategori \\
\hline \multirow{4}{*}{ I } & 1 & $-1,31$ & Negatif (Asimetris ke ukuran besar) \\
& 2 & $-0,64$ & Negatif (Asimetris ke ukuran besar) \\
& 3 & 0,19 & Mendekati simetris \\
& 4 & $-0,75$ & Negatif (Asimetris ke ukuran besar) \\
& 5 & 0,15 & Mendekati simetris \\
& 6 & $-0,39$ & Negatif (Asimetris ke ukuran besar) \\
& 1 & 0,2 & Mendekati simetris \\
II & 2 & 0,19 & Mendekati simetris \\
& 3 & 0,24 & Mendekati simetris \\
& 4 & 0,15 & Mendekati simetris \\
& 5 & 0,06 & Mendekati simetris \\
& 6 & 0,08 & Mendekati simetris \\
& 1 & 0,007 & Mendekati simetris \\
& 2 & $-0,85$ & Negatif (Asimetris ke ukuran besar) \\
III & 3 & $-1,09$ & Negatif (Asimetris ke ukuran besar) \\
& 4 & 0,11 & Mendekati simetris \\
& 5 & $-0,77$ & Negatif (Asimetris ke ukuran besar) \\
& 6 & 0,15 & Mendekati simetris \\
\hline & & &
\end{tabular}

Distribusi sedimen penyusun pantai dengan pola yang menunjukkan indikator pantai stabil umumnya dijumpai pada wilayah pantai yang lebih tenang dimana kerja dinamika oseanografi relatif kecil. Kondisi pantai seperti ini biasa terdapat pada wilayah pantai yang terlindung seperti yang dikemukakan oleh Hutabarat dan Evans, 1984.

\subsubsection{Keruncingan (Kurtosis)}

Kurtosis adalah ukuran nilai keruncingan butiran sedimen. Parameter kurtosis terdiri dari 3 kategori umum yaitu platikurtik (butiran sedimen yang tumpul), mesokurtik (butiran sedimen sedang), dan leptokurtik (butiran sedimen yang runcing). Hasil analisis kategori kurtosis terhadap butiran sedimen di pulau Maitara terlihat pada tabel 3 di bawah ini.

Hasil analisis terhadap parameter kurtosis menunjukkan bahwa distribusi butiran sedimen cenderung pada kriteria platikurtik. Hal ini berarti bahwa tingkat pergerakan dan pengangangkutan sedimen oleh faktor gelombang dan arus cukup kecil sehingga morfologi fisik butiran sedimen berbentuk tumpul. Jika sedimen banyak mengalami 
pergerakan dan pengangkutan oleh pergerakan massa air, maka sedimen akan mengalami proses pengikisan sehingga terbentuk morfologi butiran fisik sedimen yang cenderung runcing dan tajam. Pernyataan ini dipertegas oleh Komar, 1998 bahwa gerakan-gerakan sedimen terjadi dalam bentuk mengelindung, mengeser, atau bahkan bisa mendorong sedimen yang satu dengan lainnya sehingga merubah morfologi luar sedimen menjadi runcing. Secara umum, kategori karakteristik sedimen sangat dipengaruhi oleh kecepatan aliran dan faktor turbulensi.

Tabel 3. Parameter nilai dan kategori kurtosis sedimen pantai Pulau Maitara

\begin{tabular}{|c|c|c|c|}
\hline \multirow{2}{*}{ Stasiun } & \multirow{2}{*}{ Titik } & \multicolumn{2}{|c|}{ Keruncingan (Kurtosis) } \\
\hline & & Nilai $(\pi)$ & Kategori \\
\hline \multirow{6}{*}{ I } & 1 & $-0,03$ & Mesokurtik \\
\hline & 2 & $-0,02$ & Mesokurtik \\
\hline & 3 & $-0,50$ & Platikurtik \\
\hline & 4 & $-0,01$ & Mesokurtik \\
\hline & 5 & $-0,46$ & Platikurtik \\
\hline & 6 & $-0,73$ & Platikurtik \\
\hline \multirow{6}{*}{ II } & 1 & $-0,55$ & Platikurtik \\
\hline & 2 & $-0,49$ & Platikurtik \\
\hline & 3 & $-0,46$ & Platikurtik \\
\hline & 4 & $-0,22$ & Platikurtik \\
\hline & 5 & $-0,71$ & Platikurtik \\
\hline & 6 & $-0,85$ & Platikurtik \\
\hline \multirow{6}{*}{ III } & 1 & $-0,62$ & Platikurtik \\
\hline & 2 & $-0,02$ & Mesokurtik \\
\hline & 3 & $-0,04$ & Mesokurtik \\
\hline & 4 & $-0,30$ & Platikurtik \\
\hline & 5 & $-0,88$ & Platikurtik \\
\hline & 6 & $-0,35$ & Platikurtik \\
\hline
\end{tabular}

\subsection{Analisis kestabilan pantai}

Tingkat kestabilan suatu wilayah pantai ditentukan oleh energi dan gaya pembangkit berupa angin, arus, gelombang, dan pasang surut yang kemudian berperan dalam transpor dan deposisi sedimen sehingga menentukan karakteristik sedimen yang membentuk wilayah pantai. Dinamika osenografi terutama kerja energi arus dan gelombang yang berperan dalam menentukan sifat dan karakteristik sedimen pantai, pada stasiun I dari hasil pengukuran diketahui rata-rata kecepatan arusnya sebesar 0,111 $\mathrm{m} /$ det dengan rata-rata kecepatan rambat gelombang sebesar 33,36 $\mathrm{m} /$ det. Pada stasiun III rata-rata kecepatan arus sebesar $0,086 \mathrm{~m} /$ det dengan rata-rata kecepatan rambat gelombang sebesar 33,05 m/det.

Nilai kecepatan rambat arus dan gelombang yang memodifikasi material sedimen penyusun pantai di lokasi penelitian tergolong kecil, sesuai dengan Ongkosongo, 1997 sehingga cenderung menghasilkan komposisi tekstur sedimen yang 
berada pada kisaran sebaran butiran sedimen pasir sedang dan pasir halus. Adapun nilai rata-rata kecepatan arus pada stasiun II sebesar 0,069 m/det dengan kecepatan rambat gelombang rata-rata sebesar $31,65 \mathrm{~m} /$ det. Kecenderungan pola sebaran sedimen material penyusun pantai pada stasiun II adalah pasir halus dan pasir sangat halus.

Analisis tekstur, karakteristik sedimen, dan dinamika oseanografi di wilayah penelitian menunjukkan bahwa wilayah pantai bagian timur Pulau Maitara memiliki karakter pantai yang stabil yang dicirikan dengan tekstur sedimen pantai didominasi pasir halus dan sangat halus, dengan karakteristik sedimen yang tersortir sedang, tingkat kemencengan mendekati simetris, dan tingkat keruncingan platikurtik. Adapun wilayah pantai bagian utara dan selatan cenderung mengalami erosi atau termasuk kategori pantai mundur yang dicirikan dengan tekstur sedimen pantai didominasi pasir sedang dan kasar dengan karakteristik sedimen tersortir sedang dan buruk, tingkat kemencengan negatif (asimetris), dan dan tingkat keruncingan mesokurtik sampai platikurtik.

Keadaan sorting yang merupakan fungsi arus, gelombang, dan pasut turut mendukung kriteria penyortiran. Ketiga faktor Hidro-oseanografi tersebut tidak mampu untuk memilah butiran sedimen hingga menjadi seragam (tersortir baik dan sedang). Keseragaman sedimen menjadi indikator keseimbangan wilayah pantai dari deposisi dan erosi (pantai stabil). hubungan erosi dengan ukuran butiran, maka dapat dikatakan bahwa kurva kemencengan negatif merupakan indikasi proses litoral yang mengalami erosi, sedangkan kurva kemencengan positif mengalami deposisi. Distribusi tekstur dan karakteristik sedimen yang asimetris positif umumnya dibentuk oleh pasir sungai, sedangkan asimetris negatif merupakan pengikisan sedimen karena aliran yang relatif kuat, misalnya angin taufan, pecahan hempasan gelombang yang dapat memindahkan sedimen ukuran besar. Sebaran tekstur pasir sedang, menenjukkan kurva normal (mesokurtik) yaitu berada antara leptokurtik (runcing) dan platikurtik (Bruun, 1954 dan Swift, 1976).

\section{Kesimpulan}

Sedimen yang menyusun pantai Pulau Maitara didominasi oleh pasir sedang. Karakteristik butiran sedimen pantai yang menyusun Pulau Maitara menunjukkan indikasi bahwa dibagian timur Pulau Maitara merupakan wilayah pantai yang lebih stabil dibanding dibagian utara dan selatan pulau sedang dibagian barat pulau merupakan wilayah pantai berbentuk tebing curam. Wilayah pantai yang stabil dibagian timur Pulau Maitara menunjukkan bahwa proses deposisi dan erosi cenderung seimbang sedang pada wilayah pantai bagian utara dan selatan mengindikasikan proses erosi cenderung lebih besar dibanding deposisi.

\section{Daftar Pustaka}

Bruun, P. 1954. Coast Erosion and the Development of Beach Profiles, Technical Memorandum No. 44, Beach Erosion Board, U.S. Army Engineer Waterways Experiment Station, Vicksburg.

Fay, 1988. Grain size analysis. Geology of Department, Univercity Des Salam.

Folk, R.L. 1974. A review of grain size parameters sedimentology. Volume 6. pp 73-93. Hutabarat, S. dan Evans, S.M. 1984. Pengantar Oseanografi. Universitas Indonesia, Jakarta.

Lewis, D.W. 1984. Practical Sedimentology, Hutchinson Ross, Stroudsburg. 
Komar, P.D. 1998. Beach Processes and Sedimentation. Prentice Hill Inc, New Jersey.

Ongkosongo, 1997. Ongkosongo O.S.R., 1997. Dinamika Pantai: Erosi dan Sedimentasi. Kursus Pemantauan Pencemaran dan Metode Analisis Air Laut. Pusat Penelitian dan Pengembangan Oseanologi-LIPI, Jakarta

Triatmodjo, B. 1999. Teknik Pantai. Beta Offset, Yogyakarta

Swift, D.J.P. 1976. Coastal Sedimentation, Marine Sediment Transport and Environmental Management. John Wiley and Sons, New York. 